\title{
EXPLORING THE EFL STUDENTS' READING STRATEGIES USED ON READING ACADEMIC ARTICLES
}

\author{
Giwang Indriyani ${ }^{1}$ \\ ${ }^{1}$ Faculty of Education, Teacher and Training, Universitas Tidar, Magelang, Indonesia \\ (giwangindri16@gmail.com) \\ Indah Sekar Pertiwi ${ }^{2}$ \\ ${ }^{2}$ Faculty of Education, Teacher and Training, Universitas Tidar, Magelang, Indonesia \\ (indahsekar909@gmail.com)
}

\begin{abstract}
Reading activity is one of the essential skills for English language learners. Therefore, the use of reading strategies as one of the reading process rules should be considered. In considering the importance of reading strategies, this present study is intended to explore the reading strategies utilized by third-year EFL students on reading academic articles. To answer the research question, writers adopted the reading strategies questionnaire proposed by Oxford (1990). There were 21 statements and 31 samples involved in this present study. The significance of this study showed that metacognitive techniques were most frequently used by the students, followed by cognitive and affective, and then the less frequently used is social strategies. According to this finding, reading strategies should be noticed and taken as one of the considerations by lecturers and students to improve the EFL students' comprehension of reading academic articles.
\end{abstract}

Keywords: Reading; Reading Strategies; EFL; Language Learning

First Received:

(August 20, 2021)
Final Proof Received:

(September 20, 2021)

\section{INTRODUCTION}

Several people deny that reading is a crucial skill since it is used for many purposes. Some argue that developing an individual's reading skill; means expands a long-life activity. Reading activity is a part of the essential skills for English language learners. It gains diverse information from a particular text and also discovering new things. Gaining such information, the learners should pay attention to the reading process rules. Therefore, the use of reading strategies as one of the reading process rules should be considered. Several numbers of studies specifically in the EFL context revealed that a successful reader in language learning employs the reading strategies in the reading process Chen \& Chen (2015); Mistar et al., (2016); and Mudra (2018). Generally, before the process of reading begins, reading strategies are prepared first and implemented while the reading process.

As mentioned before that reading strategy plays a fundamental role in the reading activity. Interestingly, reading academic article also belong to reading activity. According 
to Subramanyam (2013), reading a scientific paper is a must for students interested in research. Scientific articles in particular fields will help one understand what has already been discovered and remain unanswered questions. Thus help in designing one's research project. Durbin (2009) asserts that academic papers are written reports of experiments on a specific study directed by a scientist who performed their experiments. In addition, the scientific article also provides detailed information on the carry-out experiments that will be useful for the readers. Unfortunately, reading an academic paper is not easy as pie since it requires concentration, strategies, and a meticulous approach. Durbin (2009) stated that reading a scientific article is categorized as hard work and takes time to do well. Meanwhile, Subramanyam R (2013) conferring that reading a scientific paper can be a frustrating experience, especially for the one who has not mastered the art of reading scientific literature. In other words, reading academics will enrich the readers' knowledge unless they know suitable strategies and meticulous approaches while reading academic articles.

Several earlier studies have been conducted as part of their topic research on learners' reading strategies. Rusmiati \& Kamalina (2017) investigate the cognitive reading strategies of EFL students. The findings show that most of the students employed resourcing, repetition, summarizing, and deduction. Likewise, Karbalaei's (2010) research study compares the reading strategy used by ESL college students in India and EFL students in Iran. According to the findings, ESL students in India prefer using global and support tactics, whereas Iranian EFL students prefer problem-solving reading strategies. In addition, Kazemi et al. (2013) conducted an empirical study on EFL students' reading techniques. To summarize, the prior studies did not conduct in-depth research on Indonesian EFL students' reading methods for academic papers.

There are research gaps in this study with the previous studies mentioned above. The Rusmiati \& Kamalina (2017)study focuses on the use of cognitive strategies proposed by O'Malley \& Chamot (1990) in reading comprehension, while this study focuses on exploring the reading strategies designed by Oxford (1990) used in reading an academic article. Then Karbalaei's (2010) study focuses on comparing the use of metacognitive awareness while reading scientific text that is influenced by socio-cultural while this study will focus on describing the reading strategies used while reading an academic article.

Considering the condition presented in the previous part, the research question is formulated as what are the type of reading strategies used by the third-year EFL students on reading academic articles?

\section{LITERATURE REVIEW}

\section{Reading}

The existence of the concept of reading has become one of the fundamental skills in language learning process. Haager et al. (2007), for instance, contended that reading is an 
activity that can be a source of someone's knowledge and delight when the reader does it strategically and collaboratively. In the same light, Jonathan Aliponga (2013) acknowledges that reading is meant to understand the reading materials' core and train the learners' critical thinking. Likewise (Chen \& Chen, 2015) conferring the opinion about reading as a mechanism of creating gist from printed and visual substantiation that involves intense practices and skills. In other words, reading is an activity that where people comprehend a particular text.

\section{Cognitive Strategies}

Ozek \& Civelek (2006) state that cognitive strategies are the most popular strategies used in reading. Cognitive strategies are used to transform or manipulate the target language by the student. It is supported by Oxford (1990) cited in Hung \& Phan Thu Ngan (2015) that stated that through reasoning, analysis, note-taking, summarizing, synthesizing, outlining, reorganizing information, the learner enables to manipulate the language material indirect ways. In the same light, (O'Malley \& Chamot (1990)) stated in Asmara (2017)reveal that using cognitive strategies in reading can help someone to be a proficient reader. In addition, Oxford (1990) in Hung \& Phan Thu Ngan (2015) asserts that cognitive strategies are used to transform or manipulate the target language by the student. In other words, these strategies start from repeating to analyzing expression than summarizing. Skimming, using another clue, reasoning deductively, summarizing, scanning, analyzing expressions, elaborating, using imagery, guessing the meaning of a new word from context, underlining, re-reading, taking notes, translating, and resourcing are some of the cognitive methods.

\section{Meta-cognitive Strategies}

Meta-cognitive strategies are defined as techniques that are planned and used carefully and intentionally by students to monitor and manage their reading. These strategies are established by considering what has previously been known about the subject, determining a reading goal, paying attention, and self-evaluation. Oxford (1990) states that by applying a metacognitive approach, the students can determine the best way to carry out the thinking processes. The metacognitive reading strategy has a significant role in reading comprehension (Mytcowicz, Goss \& Steinberg. 2014) cited in Aisah et al., (2021). It is also supported by added that metacognitive strategy has various benefits on students' reading comprehension. The significants of their study revealed that the students who utilize metacognitive strategies are recognized as successful students. Then those who do not use metacognitive strategies in their reading process.

\section{Social Strategies}

An Oxford (1990) states that social strategies are important in language learning since language is a form of behavior. In addition, Etxebarria et al. (2012) utter that social strategies correspond to those social acts that the student carries out to understand and 
study a language in a better way. Thus, social strategies are strategies that use assistantship from other people. They are displayed by cooperating with others and seeking further clarification or verification.

\section{Affective Strategies}

Affective strategies are demonstrated by using progressive relaxation, deep breathing, or meditation, as well as talking to someone about your feelings. Its goal is to learn about and convey feelings about certain reading materials, such as academic publications. According to (Oxford, 1990) affective strategies also can be applied for the learners who have a problem in learning language, especially with their emotions, anxiety or depression, or culture shock. It also states that motivation, positive attitudes and beliefs, and supportive emotions are the aspect of these strategies.

\section{METHOD}

Since this study investigated the students' strategies used on reading academic articles, the authors used a qualitative research design. Hancock (2006) believed that qualitative research is concerned with explaining opinions, experiences, and feelings of individuals producing subjective data. The authors used a questionnaire given to the thirdyear EFL students as the instrument in this study. Based on Lien \& Thi Minh Thu Tran (2017) questionnaire is a good strategy for gathering data since it allows researchers to get more participants and respondents in a short amount of time. Furthermore, it does not have to be prohibitively expensive.

The procedures in collecting the data, the authors were adopting the questionnaire from the previous research from Oxford (1990) on Strategies Useful for Reading, then request the participants to fulfill the questionnaire, and then collect the answer from the participants. The researchers analyze the data once it has been collected. The significance of this study was to look into the reading strategies utilized by EFL students on reading the academic articles. In reaching the goals of this study, there were 21 statements adopted which focused on the four categories of reading strategies; cognitive, meta-cognitive, social, and effective. The sample of this research study was 31 third-year EFL students in Indonesia. The questions formats were scale. The scales were coded as (never $=5$, rarely = 4 , sometimes $=3$, usually $=2$ and always $=1$ ). This present study used Hung \& Phan Thu Ngan, (2015) categories on the level of reading interest used. 
Table 1.

Reading Strategies Level Used by Students

\begin{tabular}{|c|c|c|c|}
\hline \multirow{2}{*}{ Active } & \multirow[t]{2}{*}{ High } & Always & 4.5 to 5.0 \\
\hline & & Usually & 3.5 to 4.4 \\
\hline \multirow{3}{*}{ Passive } & Medium & Sometimes & 2.5 to 3.4 \\
\hline & Low & Rarely & 1.5 to 2.4 \\
\hline & & Never & 1.0 to 1.4 \\
\hline
\end{tabular}

\section{RESULTS AND DISCUSSION}

\section{Results}

The outcomes from 31 respondents on students' reading strategies (cognitive, metacognitive, social, and affective) are presented in the table below.

Table 2.

Means of the Survey of Reading Strategies on Reading Academic Articles

\begin{tabular}{|c|c|c|c|}
\hline Strategies & Statements & Mean & Category \\
\hline \multirow{13}{*}{ Cognitive } & I first skim the text, then go back and read carefully. & 3.45 & High \\
\hline & $\begin{array}{l}\text { I use other clues, e.g. titles/headings, introduction, } \\
\text { transitions, etc. for better understanding. }\end{array}$ & 3.74 & High \\
\hline & I try to infer what is said, but not clearly stated in the text. & 3.32 & Medium \\
\hline & $\begin{array}{l}\text { I stop to periodically summarize what I've already read to } \\
\text { make sure it makes sense. }\end{array}$ & 3.52 & High \\
\hline & $\begin{array}{l}\text { I read quickly to get specific piece of information that I } \\
\text { want. }\end{array}$ & 3.32 & Medium \\
\hline & $\begin{array}{l}\text { I try to elaborate new information with known } \\
\text { information in mind. }\end{array}$ & 3.52 & High \\
\hline & $\begin{array}{l}\text { I try to picture or visualize information to help me } \\
\text { remember what I read }\end{array}$ & 3.61 & High \\
\hline & $\begin{array}{l}\text { When I read, I guess the meaning of unknown words or } \\
\text { phrases in context. }\end{array}$ & 3.48 & High \\
\hline & $\begin{array}{l}\text { I underline/highlight information in the text to help me } \\
\text { remember it better }\end{array}$ & 3.42 & Medium \\
\hline & $\begin{array}{l}\text { When the text becomes difficult, I re-read it to increase my } \\
\text { understanding. }\end{array}$ & 3.55 & High \\
\hline & I take notes of what I have read. & 3.03 & Medium \\
\hline & $\begin{array}{l}\text { When reading, I translate from English into my native } \\
\text { language. }\end{array}$ & 3.32 & Medium \\
\hline & $\begin{array}{l}\text { I use reference materials such as glossaries/dictionaries to } \\
\text { understand the text better. }\end{array}$ & 3.35 & medium \\
\hline
\end{tabular}




\begin{tabular}{|c|c|c|c|}
\hline \multirow[t]{4}{*}{$\begin{array}{l}\text { Meta- } \\
\text { cognitive }\end{array}$} & $\begin{array}{l}\text { Before I read, I think about what I have already known } \\
\text { about the topic. }\end{array}$ & 3.58 & High \\
\hline & I have a purpose in mind when I read. & 3.61 & High \\
\hline & $\begin{array}{l}\text { When reading, I try to stay focused on text and skip } \\
\text { unimportant parts. }\end{array}$ & 3.68 & High \\
\hline & $\begin{array}{l}\text { After I read, I check if my guesses about text are right or } \\
\text { wrong. }\end{array}$ & 3.29 & Medium \\
\hline \multirow[t]{2}{*}{ Social } & I work with my classmates to solve reading problems. & 3.10 & Medium \\
\hline & $\begin{array}{l}\text { I ask my teacher to paraphrase/explain something that is } \\
\text { not clear or does not make sense to me. }\end{array}$ & 3.06 & Medium \\
\hline \multirow[t]{2}{*}{ Affective } & I try to relax whenever I feel anxious about reading texts. & 3.58 & High \\
\hline & $\begin{array}{l}\text { I talk to my friends about my attitudes and feelings } \\
\text { concerning academic reading materials in English. }\end{array}$ & 3.16 & Medium \\
\hline
\end{tabular}

Table 2 shows us the overall means from the students' responses on reading strategies. The lowest mean is 3.03 , and the highest is 3.72 . The rest eleven items reach a high level. Meanwhile, the rest statements are categorized at a medium level. Thus from table 2 above, it is fair to believe that EFL students employ a wide range of reading strategies.

Table 3.

Means of EFL Students' Reading Strategies on Reading Academic Articles

\begin{tabular}{lll}
\hline Strategy & Items & Mean \\
\hline Cognitive & $1,2,3,4,5,6,7,8,9,10,11,12,13$ & 3.43 \\
Meta-cognitive & $14,15,16,17$ & 3.54 \\
Social & 18,19 & 3.08 \\
Affective & 20,21 & 3.37 \\
\hline Total & & 3.41 \\
\hline
\end{tabular}

Table 3 provides us the information about the question items that represent each strategy. It also shows that the mean for cognitive strategy gains 3.43, metacognitive (3.54), social (3.08), and affective (3.37). Furthermore, the total means of the four categories in reading strategy was 3.41. Only social strategies gained a medium level, while the three other strategies obtained a high level.

\section{Discussion}

The present study explores the type of reading strategies used by the third-year EFL students on reading academic articles. From the students' questionnaire above, the 
researchers conclude several points regarding reading strategies employed by the thirdyear EFL scholar in Indonesia. It can be seen that the mean of 21 statements reflected four reading strategies proposed by Oxford (1990).

First, the cognitive strategy obtained the highest that show in clue-using, the questionnaire number two. The mean score is 3.74 belong to a high-level category, which means that clue-using is usually used as a reading strategy when the students read an academic article. Second, the meta-cognitive gains a 3.68 total mean score on the attention-paying category. The result is categorized as a high level of reading strategy and is usually used by the students. The social strategy cooperating category obtained the highest mean score, 3.10. It indicates that cooperating category is recognized into the reading strategies' medium level and sometimes utilized by the students while reciting academic articles. The last, the affective strategy's highest mean is 3.58 gained in the anxiety-lowering category. Based on the score, it can be categorized as the high level of reading strategies and usually employed by the pupils in reading the academic articles.

The study revealed that EFL students have diverse types of reading strategies to recite scientific articles. Based on the result, the most employed strategy by the EFL students is the metacognitive strategies on attention-paying. In the attention-paying section, students are trying to focus on what being discuss and skip unimportant parts of academic articles. Focus on what matters and leave useless information will help the students to maximize students' comprehension and productivity in reading scientific papers. Therefore, it is in line with what has been studied by Aisah et al. (2021), in which they come across that metacognitive strategy influences the students' reading comprehension better since the students were planning, monitoring, and evaluating their reading activity. Memiş \& Bozkurt (2013) also emphasized that students who employ metacognitive strategies will have better comprehension, problem-solving skills, and organized knowledge. To summarize, knowledge about the kinds of reading strategies on reading academic articles for university students is crucial. These results indicate that reading strategies are important for increasing the students' reading comprehension toward specific academic articles.

Consequently, although this present study has provided a plain explanation about students' reading strategy on reading the academic article but hope it will be compelling samples in the reading strategies used, especially for reading a scientific paper. Further researchers are expected to explore more on how effective a specific reading strategy (cognitive, metacognitive, social, or affective strategy) is on reading the academic article.

\section{CONCLUSION}

This recent research provides an insight into the EFL students' reading strategies among Indonesian third-year university students by investigating their reading strategies when reading academic articles. The result showed meta-cognitive techniques were most 
frequently used by the students, followed by cognitive and affective, and then the less frequently used is social strategies. In terms of EFL students, the following reading methods are most commonly utilized when they are reading academic articles: clue-using, imagery-using, and attention-paying. As a result, the findings of this research may aid lecturers in determining appropriate reading practices to improve learners' comprehension of research papers. In conclusion, to improve the students' reading comprehension on academic papers, the students must also have knowledge and understanding of what reading strategies should be employed and how to apply them.

\section{REFERENCES}

Aisah, N., Surtiana, R, L., \& Nurjamin. (2021). Metacognitive Strategies in Student's Reading Comprehension. English Education and Applied Linguistics (EEAL) Journal 20, 4(1), 20-29.

Asmara, N. I. (2017). An Analysis of Cognitive Reading Strategies Used in Reading Comprehension. Conaplin 82(9), 304-307. https://doi.org/10.2991/conaplin16.2017.69

Chen, K. T. C., \& Chen, S. C. L. (2015). The Use of EFL Reading Strategies Among High School Students in Taiwan. The Reading Matrix: An International Online Journal, 15(2), 156-166.

Durbin, C. G. (2009). How to Read A Scientific Research Paper. Respiratory Care, 54(10), 1366-1371.

Etxebarria, A., Garay, U., \& Romero, A. (2012). Implementation of Social Strategies in Language Learning by Means of Moodle. Journal of Language Teaching and Research, 3(2). https://doi.org/10.4304/jltr.3.2.273-282

Hancock, B. (2006). An Introduction to Qualitative Research Authors. Qualitative Research, 4th, 504. https://doi.org/10.1109/TVCG.2007.70541

Hung, D. M., \& Phan Thu Ngan, V. (2015). Investigating Reading Strategies Used by EFL Students at Dong Thap University. Asian Journal of Educational Research 3(4), 1020.

Jonathan Aliponga. (2013). Reading Journal : Its Benefits for Extensive Reading Extensive Reading. International Journal of Humanities and Social Science, 3(Humanities and Behavioral Science), 73-80.

Karbalaei, A. (2010). A Comparison of the Metacognitive Reading Strategies Used by EFL and ESL Readers. The Reading Matrix, 10(2), 165-180. http://www.readingmatrix.com/articles/sept_2010/alireza_karbalaei.pdf

Kazemi, M., Hosseini, M., \& Kohandani, M. (2013). Strategic Reading Instruction in EFL Contexts. Theory and Practice in Language Studies, 3(12), 2333-2342. https://doi.org/10.4304/tpls.3.12.2333-2342

Lien, C., \& Thi Minh Thu Tran. (2017). An Evaluation of Using Games in Teaching English Grammar for First Year English-Majored Students at Dong Nai Technology University. International Journal of Learning, Teaching and Educational Research, 16(7), 55-71. 
Memiş, A., \& Bozkurt, M. (2013). The Relationship of Reading Comprehension Success with Metacognitive Awareness, Motivation, and Reading Levels of Fifth Grade Students. Educational Research and Reviews, 8(15), 1242-1246. https://doi.org/10.5897/ERR2013.1544

Mistar, J., Zuhairi, A., \& Yanti, N. (2016). Strategies Training in the Teaching of Reading Comprehension for EFL Learners in Indonesia. English Language Teaching, 9(2), 49. https://doi.org/10.5539/elt.v9n2p49

Mudra, H. (2018). Metacognitive Online Reading Strategies among Pre-Service EFL Teachers in Indonesia. Educational Process: International Journal, 7(2), 151-164. https://doi.org/10.22521/edupij.2018.72.5

Ozek, Y., \& Civelek, M. (2006). A Study on the Use of Cognitive Reading Strategies by ELT Students. The Asian EFL Journal, August, 1-26. http://www.asian-efljournal.com/PTA_August_06_ozec\&civelek.pdf

Rusmiati, R., \& Kamalina, K. (2017). The Use of Direct Strategies in Reading Comprehension. Getsempena English Education Journal, 3(2), 217646. 